\title{
"É UMA MENINA!": MARCAS DA EDUCAÇÃO FEMININA E RELAÇÕES DE GÊNERO NA FAMÍLIA
}

\author{
Míria Izabel Campos ${ }^{1}$ e Magda Sarat ${ }^{\text {iD } 2}$
}

\section{Resumo}

Pensar diferenças e desnaturalizar desigualdades se faz necessário, pois o caminho para conquista de relações de gênero equânimes é longo, com avanços e recuos no processo. Neste contexto, a proposta é trazer para o debate a educação feminina e as relações de gênero vivenciadas na família, figuração entendida a partir da teoria do processo civilizador como constituída por teias de interdependência. Assim, o objetivo foi identificar e problematizar relações de gênero que permearam a educação feminina presentes em histórias escritas por mulheres/acadêmicas de Pedagogia, da Universidade Federal da Grande Dourados (UFGD), Mato Grosso do Sul. O corpus da pesquisa foi formado por 20 memoriais de infância (auto)biográficos, documentos do arquivo pessoal de professora da referida universidade. Utilizaram-se para análises o referencial teórico eliasiano, abordagem (auto)biográfica e estudos de gênero. Os resultados apontaram que meninas e meninos carregam marcas dos contextos os quais se originam, pois são dependentes do seu grupo familiar para se situarem no mundo. Evidenciou-se que a infância de meninas está condicionada a uma educação coercitiva e formas de submissão e controle estabelecidos a elas, que comparada à história dos meninos, sugere desequilíbrio entre os gêneros. Porém, as problematizações dão conta de processos de transformação em curso. Sendo assim, conclui-se, a família foi lembrada como figuração que marcou a vida das mulheres/acadêmicas, mas ao rememorarem suas infâncias podem ter compreendido que nas relações interdependentes elas são constituídas, mas também constituem tais relações. Portanto, a depender de suas posturas e ações será possível vivenciar tempos de maior equilíbrio da balança de poder.

Palavras-chave: Processo civilizador; (Auto)biografia; Formação inicial; Figuração; Poder.

\footnotetext{
${ }^{1}$ Doutora em Educação. Professora Adjunta da Universidade Federal da Grande Dourados (UFGD). Docência na Graduação. Pesquisadora Vice-Líder do Grupo de Pesquisa Educação e Processo Civilizador (GPEPC). E-mail: miriacampos@ufgd.edu.br

${ }^{2}$ Doutora em Educação. Professora Associada da Universidade Federal da Grande Dourados (UFGD). Docência na Graduação e na Pós-Graduação. Pesquisadora Líder do Grupo de Pesquisa Educação e Processo Civilizador (GPEPC). E-mail: magdaoliveira@ufgd.edu.br
} 


\section{"IT'S A GIRL!": MARKS OF FEMALE EDUCATION AND GENDER RELATIONS IN THE FAMILY}

\section{Abstract}

It is necessary to think about differences and denaturalize inequalities, because the path to achieve equal gender relations is long, with advances and setbacks along the way. In this context, our proposal is to bring to the debate the female education and gender relations experienced in the family, figuration understood in the theory of civilizing process as something constituted by networks of interdependence. Thus, the aim was to identify and problematize gender relations that permeated female education, present in stories written by women/academics from the Pedagogy School from the Universidade Federal da Grande Dourados (UFGD), Mato Grosso do Sul. The research corpus was composed by 20 autobiographic childhood memorials, documents from the teachers' personal archive. In our analysis, we used the eliasiano theoretical framework, (auto)biographical approach, and gender studies. The results showed that girls and boys carry marks of the context where they come from, since they are dependent on their family groups in order to situate themselves in the world. It proved that girls' childhood is conditioned not only by a coercive education, but also by ways of submission and control stablished for them, which, when compared to the boys' history, suggests an unbalance between genders. However, the problematizations account for some ongoing transformation processes. Thus, we concluded that the family was remembered as figuration that marked women/academics' lives. However, in recollecting their childhood they might have comprehended that, within the interdependent relationships, they were constituted themselves, but they also constituted such relationships. Therefore, depending on their attitudes and actions, it will be possible to experience times of a greater equilibrium in the balance of power.

Keywords: Civilizing Process; (Auto)biography; Initial Development; Figuration; Power.

\section{Introdução}

Aí começa a história da minha vida, porque minha mãe tinha um filho menino que era "terrível" [...]. Quando meu irmão tinha 4 anos minha mãe engravidou. Ao ela ir ao médico e fazer um ultrassom o médio disse que era um belo menino. [...]. Porém, quando ela foi para a maternidade ganhar o bebê [...] o médico disse a ela quando eu nasci: "É uma menina!" Isso sem dúvidas, disse minha mãe, foi uma alegria, pois ela sempre sonhou ter um casal de filhos, e todos na família ficaram muito felizes (mesmo eu tendo de usar roupinhas de menino!!). (Memorial de infância, 2013/3, p. 1, grifos nossos) ${ }^{1}$.

\footnotetext{
${ }^{1}$ Registramos que todas as acadêmicas, cujos memoriais de infância aparecem neste artigo, assinaram Termo de Consentimento Livre e Esclarecido (TCLE). 
Como no excerto que abre este texto, muitas são as histórias das mulheres/acadêmicas escritas nos 20 memoriais de infância (auto)biográficos ${ }^{1}$ que formam o corpus documental da nossa pesquisa, nas quais evidenciamos questões das relações de gênero presentes na família - "filho menino que era 'terrível'"; "um belo menino"; a exclamação na expressão "É uma menina!"; e, por último, mas não menos intrigante, "mesmo eu tendo de usar roupinhas de menino". Assim, entendemos ser importante voltarmos a atenção aos conceitos naturalizados, tidos como sendo da essência de meninas/mulheres e meninos/homens, muitas vezes marcando-as/os mesmo antes de nascerem e que, em certa medida, determinam expectativas de comportamentos para cada gênero.

Estamos considerando gênero a partir dos escritos de Scott (1995, p. 86), quer seja, "[...] numa conexão integral entre duas proposições: (1) o gênero é um elemento constitutivo de relações sociais baseadas nas diferenças percebidas entre os sexos; e (2) o gênero é uma forma primária de dar significado às relações de poder". Nesse sentido, questionar verdades e/ou certezas passadas de geração para geração é indispensável se quisermos viver em uma sociedade igualitária e de respeito às diferenças, na qual todas e todos possam escolher maneiras de ser e viver, sabendo que não precisarão responder a algo prédeterminado, ou seja, não necessitarão viver uma vida definida a priori.

A partir deste contexto, definimos como objetivo identificar e problematizar relações de gênero que permearam a educação feminina presentes em histórias escritas por mulheres/acadêmicas de Pedagogia, da Universidade Federal da Grande Dourados (UFGD), Mato Grosso do Sul. Compreendemos que estas e tantas outras histórias das mulheres necessitam ser visibilizadas para que possamos conhecê-las e colocá-las na pauta dos debates, buscando enaltecer diferenças e desnaturalizar desigualdades, pois apreendemos que historicamente o caminho para a conquista de relações de gênero equânimes é longo e com muitos avanços e recuos no processo.

Ao mencionarmos sobre os caminhos é fundamental escrevermos que, no nosso país, víamos alcançando êxitos na área dos direitos de cidadãs e cidadãos desde o final da década de 1970, a partir de diferentes contextos de lutas sociais, movimentos sindicais, movimento de mulheres, entre outros, os quais continuaram em um crescente, principalmente, com o término do período da Ditadura Militar ${ }^{2}$, adentrando ao novo século com perspectivas de que mais avanços viriam e conquistas seriam consolidadas.

Contudo, o momento histórico vivido por todas e todos no cenário social e político das campanhas nos primeiro e segundo turnos das eleições para o cargo

\footnotetext{
${ }^{1}$ Importante marcar que os documentos que formam o corpus da pesquisa são denominados originalmente "memoriais de infância". A nomenclatura "memoriais de infância (auto)biográficos" foi cunhada por Campos (2018), a partir de estudos teóricos com a abordagem (auto)biográfica.

${ }^{2}$ Ditaduras quase sempre possuem caráter excepcional (constituem regimes de exceção) e surgem a partir de golpes de Estado. No caso do Brasil a Ditadura Militar iniciou-se com o golpe em 1964, perdurando até 1985. Para saber mais citamos: Chiavenatto (1995); Ferreira e Gomes (2014); Silva (2006).
} 
de Presidente do Brasil - ano de 2018 - foi marcado pelo acirramento de ataques e falas discriminatórias contra mulheres, negros, populações pobres, bem como a toda comunidade $\operatorname{LGBTQIA}+{ }^{1}$. Com o resultado consumado nas urnas vivenciamos a continuidade, ampliação e aprofundamento de discursos desrespeitosos, hostis, truculentos, traduzindo-se em aumento dos índices de violências e mortes das populações já citadas, restrições de direitos, sucessivos casos de censura às liberdades etc. Especificamente relativo à temática das diversidades, vimos acompanhando o recrudescimento das discussões e desmontes de políticas já conquistadas, caracterizando um significativo recuo, com repercussões que puderam/podem ser sentidas na família, na educação básica e na educação superior, para citar algumas das figurações envolvidas nesses processos.

Relatado por outra das mulheres/acadêmicas, trazemos o trecho a seguir que traduz uma realidade ainda muito presente hoje em diversas famílias:

Minha infância começou logo após o meu nascimento, minha mãe tinha o sonho de ter uma filha com muita saúde e perfeita, enquanto meu pai se preocupava apenas com o sexo, seu sonho era ter um filho homem [...]. (Memorial de infância, 2013/1, p. 2).

São registros que denotam marcas na educação feminina, pois quando foi possibilitado a elas trazerem à tona suas histórias, as mulheres/acadêmicas relembraram desigualdades nas relações de gênero presentes em suas vidas na família.

Por esse ângulo, percebemos necessário contribuir com indagações acerca da educação feminina e as relações de gênero vivenciadas na família, figuração entendida por nós como constituída por teias de interdependência, isto significando, a partir de uma lógica relacional baseada na perspectiva teórica eliasiana, que as pessoas

[...] através das suas disposições e inclinações básicas são orientadas umas para as outras e unidas umas às outras nas mais diversas maneiras. Elas constituem teias de interdependências ou figurações de muitos tipos, tais como famílias, escolas, cidades, estratos sociais ou estados. (ELIAS, 2008, p. 15).

A discussão em tela no texto se pronuncia e, portanto, depreendemos ser pertinente tratarmos de "[...] como se entrelaçam as relações de interdependência e poder [...]" (VEIGA, 2009, p. 27) na família, com foco nas relações de gênero.

Com suporte no referencial teórico eliasiano apreendemos que "o conceito de equilíbrio de poder permite [...] a conceitualização de matizes e graus nos diferenciais de poder dos grupos humanos" (ELIAS, 2020, 37). E ao

${ }^{1}$ LGBTQIA+: Lésbicas, Gays, Bissexuais, Transexuais, Queer, Intersexo, Assexual. O + é utilizado para incluir outros grupos e variações de sexualidade e gênero. Disponível em: https://www.educamaisbrasil.com.br/educacao/dicas/qual-o-significado-da-sigla-lgbtqia.

Acesso em: 18 fev. 2021. 
aprofundarmos em Elias (2008), evidenciamos, o poder não é algo que se tem, ou que uns têm e outros não. O poder é parte constituinte das relações entre os indivíduos e entre estes e a sociedade, entendidas como relações interdependentes. Dessa forma, as relações em família lembradas nos memoriais de infância (auto)biográficos se destacam como significativas para identificarmos e problematizarmos o diferencial e/ou o gradiente da balança de poder nas infâncias de meninas.

Isto posto, seguimos para apresentar e circunstanciar tempos e lugares das mulheres/acadêmicas.

\title{
2. Lócus, corpus documental e a pesquisa (auto)biográfica
}

\begin{abstract}
Morava em uma rua de chão $[. .$.$] , em uma casa simples de madeira, que$ nem banheiro tinha [...] minha mãe nunca estudou, sabia ler e escrever e meu pai era pedreiro analfabeto, éramos muito pobres, me lembro de comprar roupas só no natal, e nunca íamos a um mercado para fazer compras, comprávamos em um mercadinho na nossa vila, e o dono anotava tudo em uma caderneta. (Memorial de infância, 2014/1, p. 2).
\end{abstract}

O Mato Grosso do Sul (MS), estado localizado na região Centro-Oeste do Brasil, se constituiu a partir da divisão de Mato Grosso Uno, tendo sido criado a partir a Lei Complementar no 31 de 11 de outubro de 1977¹. Hoje com 43 anos, portanto um estado jovem, é formado por 79 municípios e pelo censo de 2010 encontrava-se com uma população total de 2.449 .024 (IBGE) ${ }^{2}$. A população estimada pelo Instituto de Geografia e Estatística para 2020 seria de 2.809.394 pessoas. Ainda segundo dados do Instituto, a área desta unidade federativa é de $357.147,994 \mathrm{~km}^{2}$, tendo sua densidade demográfica definida em 6,86 $\mathrm{hab} / \mathrm{km}^{2}$.

Por se constituir em um estado formado por pessoas advindas de outras regiões do Brasil, principalmente incentivados por propaganda governamental conhecida como "Marcha para o Oeste", a maioria deles veio com a intenção de trabalhar nas históricas terras devolutas ${ }^{3}$. Muitos prosperaram bastante e hoje o estado de Mato Grosso do Sul é reconhecido nacionalmente por sucessivas produções agropecuárias recordes, como pode ser lido em Peres (2021), no Portal do Governo do Estado 4 .

Diante de um cenário composto por grandes propriedades, evidenciamos a partir de pesquisas empreendidas em estudo mais amplo (Doutorado em Educação), que além de possuir um número reduzido de municípios, estes

\footnotetext{
1 Para conhecer e saber mais acerca da história da divisão do estado sugerimos Bittar (2009a; 2009b).

2 Disponível em: https://cidades.ibge.gov.br/brasil/ms/panorama. Acesso em: 20 fev. 2021.

3 Para ver sobre "Marcha para o Oeste" e terras devolutas indicamos Amaral (2014) e Oliveira (2002).

4 Disponível em: http://www.ms.gov.br/valor-da-producao-agropecuaria-de-mato-grosso-dosul-chega-ao-recorde-de-r-709-bilhoes/. Acesso em: 20 fev. 2021.
} 
geralmente possuem um número pequeno de habitantes. Fundamentado nessa realidade do estado, vale lançarmos nosso olhar ao trecho escrito pela acadêmica, o qual inicia esta seção, realçando que ainda hoje muitas cidades de Mato Grosso do Sul conservam casas de madeiras, ruas de terra e outras características de um estado do interior do Brasil.

Preparamos o Quadro 1, que segue, visando trazer um demonstrativo das cidades de origem das mulheres/acadêmicas que elaboraram os memoriais de infância (auto)biográficos, os quais constituem o corpus documental da nossa pesquisa.

Quadro 1: Cidades de origem das mulheres/acadêmicas.

\begin{tabular}{|l|l|}
\hline Cidades & População 2010 - Estimada 2020 \\
\hline 1- Amambai & $34.730-38.826$ pessoas \\
\hline 2- Caarapó & $25.767-30.593$ pessoas \\
\hline 3- Dourados & $196.035-225.495$ pessoas \\
\hline 4- Fátima do Sul & $19.035-19.170$ pessoas \\
\hline 5- Glória de Dourados & $9.927-9.950$ pessoas \\
\hline 6- Rio Brilhante & $30.663-38.186$ pessoas \\
\hline
\end{tabular}

Fonte: Organização Campos (2021), a partir de dados do IBGE ${ }^{1}$.

Os 20 memoriais de infância (auto)biográficos foram escritos por mulheres/acadêmicas nascidas nas décadas de 1980 e 1990 nas 6 cidades apresentadas no Quadro 1. Quando elaboraram os referidos documentos todas elas eram estudantes do curso de Pedagogia da Universidade Federal da Grande Dourados (UFGD), localizada no interior de Mato Grosso do Sul e cursavam disciplinas relativas à infância e educação infantil. Os memoriais de infância (auto)biográficos foram produzidos pelas mulheres/acadêmicas e recolhidos pela professora nos anos de 2013, 2014, 2016 e 2017. Para maior exposição de dados acerca do corpus documental organizamos o Quadro 2, o qual apresentamos a seguir.

\footnotetext{
${ }^{1}$ Dados disponíveis em: https://www.ibge.gov.br/cidades-e-estados/ms/amambai.html; https://www.ibge.gov.br/cidades-e-estados/ms/caarapo.html; https://cidades.ibge.gov.br/brasil/ms/dourados/panorama; https://www.ibge.gov.br/cidades-e-estados/ms/fatima-do-sul.html; https://cidades.ibge.gov.br/brasil/ms/gloria-de-dourados/panorama; https://www.ibge.gov.br/cidades-e-estados/ms/rio-brilhante.html. Acesso em: 08 mar. 2021.
} 
Quadro 2: Corpus documental.

\begin{tabular}{|l|l|l|}
\hline Cidades & $\begin{array}{l}\text { Memoriais de } \\
\text { infância } \\
\text { (auto)biográfi } \\
\text { cos }\end{array}$ & $\begin{array}{l}\text { Anos dos nascimentos das } \\
\text { mulheres/acadêmicas }\end{array}$ \\
\hline Caarapó & 1 & $1980(1)$ \\
\hline Dourados & 6 & $1981(1) ; 1982(1) ; 1985(1) ; 1989(3)$ \\
\hline Fátima do Sul & 1 & $1988(1)$ \\
\hline Amambai & 1 & $1993(1)$ \\
\hline Dourados & 7 & $1990(1) ; 1992(1) ; 1994(2) ; 1995(2) ; 1996(1)$ \\
\hline Fátima do Sul & 2 & $1996(2)$ \\
\hline $\begin{array}{l}\text { Glória de } \\
\text { Dourados }\end{array}$ & 1 & $1998(1)$ \\
\hline Rio Brilhante & 1 & $1994(1)$ \\
\hline
\end{tabular}

Fonte: Organização Campos (2021).

Relativo ao corpus documental da pesquisa é preciso registrarmos, mesmo brevemente pois não abarca o objetivo da discussão no presente artigo, que ele é parte constituinte de arquivo pessoal de uma professora da referida universidade. Os documentos foram acessados, lidos, organizados, ou seja, foi inventariada parte do arquivo pessoal da professora que foi disponibilizada para o estudo (CAMPOS, 2018).

Por esse ângulo de trabalho com arquivos pessoais citamos Cunha (2017, p. 195) para quem "a arte de guardar que compõe a essência da existência dos arquivos torna-se necessária, no intuito de não apenas preservar memórias, mas também de servir de fonte/documentos à produção historiográfica". Para nós, a investigação realizada nos referidos documentos foi ao encontro do entendimento de que é fundamental diversificarmos e ampliarmos o espectro das pesquisas, pois isto viabilizará o acesso a muitas e diferentes histórias, as quais podem estar guardadas e conservadas em arquivos pessoais e outros fundos.

Em Ducrot (1998, p. 154-155) temos que um fundo "[...] é um conjunto que se basta a si mesmo [...] Esse é o caso de todas as pessoas e, portanto, seus arquivos constituem um fundo". No Brasil, a Lei no 8.159 de 8 de janeiro de 1991, em seu Art. 11 define que "consideram-se arquivos privados os conjuntos de documentos produzidos ou recebidos por pessoas físicas ou jurídicas, em decorrência de suas atividades" (BRASIL, 1991, n. p.). Dentre os arquivos privados, têm-se arquivos econômicos, arquivos sociais e arquivos pessoais, sendo que o último corresponde ao caso do estudo por nós realizado (BELLOTTO, 2015).

Feitas essas considerações, acentuamos mais uma vez Cunha (2017, p. 189) quando explicita que "a descoberta e a pesquisa nos arquivos pessoais propiciou ao historiador reflexões por colocarem em cena novos autores, novos objetos e novas fontes". Tal premissa nos leva a destacar a relevância de estudos com os arquivos pessoais, observando que os documentos acumulados e 
preservados pela professora, oriundos de suas atividades na universidade, estão a cumprir a função de contribuir com a produção historiográfica em diferentes perspectivas, quer sejam, História da Educação no Mato Grosso do Sul, História das Mulheres e Estudos de Gênero.

Como já apontamos anteriormente, a pesquisa em tela foi realizada com mulheres/acadêmicas de Pedagogia e, nesse sentido, tendo como referência Bueno (2002, p. 21) indicamos que os trabalhos com memoriais (auto)biográficos de acadêmicos/as ainda são "mais escassos, pois [...] empregam o método com grupos de indivíduos que ainda não ingressaram na vida profissional". A vista disso, salientamos que o estudo em questão somouse ao grande número de trabalhos desenvolvidos a partir da abordagem (auto)biográfica construindo, não obstante, um viés diferenciado quando optamos pelo foco em histórias de mulheres ainda em processo de formação inicial, as quais, no nosso entendimento, puderam vivenciar uma experiência ímpar de rememorar suas infâncias antes de adentrarem ao trabalho como professoras de crianças que poderão vir a ser.

Para contribuir com as argumentações acerca de trabalhos desenvolvidos com a abordagem (auto)biográfica citamos Souza (2006, p. 24) quando ele expressa que "[...] a história de vida como um relato oral ou escrito, recolhido através de entrevista ou de diários pessoais, objetiva compreender uma vida, ou parte dela, como possível para desvelar e/ou reconstituir processos históricos [...]". Nessa perspectiva, realçamos que nas histórias escritas pelas mulheres/acadêmicas a infância, como parte de suas vidas, se pronunciou como um período marcante, do qual vivências e relações emergiram como significativas. Na sequência apresentamos mais um excerto de uma das mulheres/acadêmicas, buscando dialogar com seu relato:

O interessante de falar sobre infância, sobre a própria infância é que você mexe com a sua cabeça, com os seus sentimentos, você é capaz de se lembrar de coisas vividas muitos anos atrás. (Memorial de infância, 2016/4, p. 2).

Por esse ângulo, evidenciamos como pode ser significativo trabalhar com narrativas, memoriais (auto)biográficos, memoriais de formação, histórias de vidas e outros, pois a partir dessas metodologias "[...] os indivíduos dão forma à suas experiências e sentido ao que antes não tinha, [...] constroem a consciência histórica de si e de suas aprendizagens nos territórios que habitam e são por eles habitados" (PASSEGUI; SOUZA; VICENTINI, 2011, p. 371). Apoiadas nessa afirmação entendemos que as mulheres/acadêmicas de Pedagogia, vivenciando a possibilidade de escrever os seus memoriais de infância, se reconectaram a lugares e tempos de suas infâncias, podendo muitas delas terem alcançado uma consciência maior de suas experiências e relações, isto significando, uma oportunidade de assimilar as teias de interdependências nas quais se constituíram e ajudaram a constituir.

A vista disso, ao optarmos pelo trabalho com a abordagem (auto)biográfica e sua interface com a educação, devemos assinalar o quão 
valiosos podem ser estes diálogos. E para corroborar com nossa percepção aludimos a Josso (2020) quando ela chama a atenção para a dinâmica que se pode construir na condução de aprendizados os quais, para além dos conhecimentos gerados, causem impactos e transformação na formação pessoal e social dos indivíduos. Explicitando assim, ela cuida de alertar que tal posição não significa afirmar que "[...] o paradigma biográfico resolva todos os problemas, mas é uma contribuição relevante e significativa para ter uma atitude ativa na vida da comunidade que leva em consideração as interdependências" (JOSSO, 2020, p. 47).

Pela ótica das relações interdependentes, quer seja, buscando entender as teias nas quais indivíduos e sociedade estão enredados, devido ao foco de discussão neste artigo antes de adentrarmos à próxima seção é mister assinalarmos a perspectiva conservadora e de status violento em relação às mulheres, o qual o estado de Mato Grosso Sul figura. De acordo com documento publicado pelo Tribunal de Justiça de Mato Grosso do Sul - Coordenadoria Estadual da Mulher em Situação de Violência Doméstica e Familiar -, "o conceito de feminicídio surgiu na década de 1970 para contestar a invisilibilização dos assassinatos de mulheres em todo o mundo" (MATO GROSSO DO SUL, 2019, n. p.). Isto significa, precisamos nos compromissar e nos dispor a tirar do "[...] fundo da vida social" (ELIAS, 2011, p. 123) o massacre histórico de mulheres. Sendo assim, do mesmo documento também destacamos aqui que:

O Estado brasileiro ocupa a $5^{a}$ posição no ranking mundial de assassinato de mulheres, é o quinto país mais violento para elas. Já segundo o Mapa da Violência 2015, o estado de Mato Grosso do Sul possui uma taxa de 5,9 assassinatos de mulheres para cada 100 mil mulheres sul-mato-grossenses. Em São Paulo, a taxa é de 2,9. (MATO GROSSO DO SUL, 2019, n. p).

Diante deste cenário de Brasil e estado de Mato Grosso do Sul torna-se iminente sobrelevar que muitas são as histórias e muitos são os caminhos que levaram/levam a uma perpetuação da violência. Nascer e crescer nesses contextos pede que se tenha um cuidado a mais e sempre, para que histórias de feminicídios, silenciamentos, invisibilazações, preconceitos de raça, etnia, geração, orientação sexual, gênero, dentre tantas outras formas de ataques à integridade física, moral, psicológica e patrimonial sejam definitivamente abolidas da realidade de todas as mulheres. Por conseguinte, compreendemos ser primordial começar na família um cuidado e uma educação equânime para meninas e meninos.

De outra maneira escrevemos, "informar, esclarecer, minimizar o preconceito e promover a equidade de gêneros parece ser um caminho longo [...]" (ALVES; PESTANA; MARQUES, 2020, p. 130), mas de responsabilidade de todas e todos para que efetivamente possamos vivenciar tempos diferentes. Dessa maneira, cabe a nós fazermos a nossa parte, no sentido de contribuirmos para mudar o rumo da história. 


\section{Marcas da educação feminina e as relações de gênero na família}

[...] os momentos com a família e amigos tornam o ser humano mais solidário, pois assim me sinto quando penso em tudo que vivi com as pessoas que me rodeiam. (Memorial de infância, 2016/1, p. 1).

Com Elias (2012, p. 470) aprendemos ser fundamental saber que "[...] as crianças formam um grupo social particular", mas vivem em interdependência com os adultos. A partir dessa afirmação e de excerto da obra do autor que estará citado a seguir, assimilamos a perspectiva defendida por ele acerca das teias de interdependência nas quais o indivíduo nasce e cresce, constituindo a sociedade e se constituindo nela. Em outros termos, sociedade e indivíduos vivem um processo social e são, concomitantemente, produtores desse processo.

Todo indivíduo nasce num grupo de pessoas que já existiam antes dele. E não é só: todo indivíduo constitui-se de tal maneira, por natureza, que precisa de outras pessoas que existam antes dele para poder crescer. [...] É assim que efetivamente cresce o indivíduo, partindo de uma rede de pessoas que existiam antes dele para uma rede que ele ajuda a formar. (ELIAS, 1994, p. 2627-35).

Especificamente sobre as memórias relativas à infância na família, nosso centro de interesse aqui, trazemos mais uma vez Elias (2001) em trecho de entrevista realizada com o autor. Quando foi perguntado sobre como se sentia em casa, assim ele respondeu:

Eu sabia que meu pai e também minha mãe fariam tudo por mim. [...] Talvez eu possa formular da seguinte maneira: assim como os astrônomos descobriram que todo o universo repercute ruídos consecutivos ao Big Bang inicial, assim os homens trazem em si, no que diz respeito às suas vidas, uma intuição cuja origem remonta aos primeiros momentos passados em sua família. (ELIAS, 2001, p. 21-22).

Observamos como na sua resposta ficam explícitas o quanto foram significativas as suas primeiras experiências vividas na família. A infância segura, a situação de alento provocada pela certeza de poder contar com o pai e a mãe em diferentes vivências e demandas da vida o marcaram e o constituíram emocionalmente de forma a possibilitá-lo lidar com as adversidades que surgiram. E, obviamente, ficou perceptível nas suas ponderações como experiências de aconchego se espraiaram por sua trajetória, repercutindo em uma convicção de que os pais o apoiariam em diferentes acontecimentos e conjunturas.

Ainda nesse sentido, destacamos em Elias (2001) a passagem na qual ele relata sobre sua infância muito doente, quando podia contar com o cuidado extremo dos pais, e como tal situação foi geradora de uma confiança inabalável 
e bastante marcante no seu percurso de vida. Segundo Elias (2001, p. 22), "é por essa sensação de grande segurança que usufruí durante minha infância que explico minha perseverança, mais tarde, na época em que escrevia e ninguém prestava atenção em mim"1.

Por esse entendimento em relação à dimensão das vivências na família, daquilo que é usufruído na infância e das repercussões ao longo da vida, temos dois excertos a seguir, os quais foram retirados de memorial elaborado por uma das mulheres/acadêmicas participante da nossa pesquisa:

Meus pais sempre me trataram com muito respeito e com muito amor, por isso sou a pessoa que sou hoje, a família é o mais importante para o desenvolvimento de uma criança [...]. Minha família foi muito importante para o meu crescimento, eles sempre me ajudaram a superar qualquer problema e sempre esteve presente na vida, sempre conversaram comigo me aconselhando [...]. (Memorial de infância, 2014/4, p. 3-6).

E continuando na história, nós temos na sequência um trecho no qual ela relata fato muito contundente vivido na sua infância:

Para finalizar minha história de infância deixei para o final algo que para mim é muito triste e que me deixa magoada ao lembrar. Eu nunca falo a respeito disso para ninguém, somente falei para meus pais na época em que tudo ocorreu. Quando tinha oito anos, meu tio irmão do meu pai veio me acariciar. [...] quando minha mãe chegou, contei para ela o que tinha acontecido, e ela teve uma conversa séria com ele, e nunca mais me deixou próxima dele. [...] meus pais sempre acreditaram em mim e nunca me abandonaram [...]. (Memorial de infância, 2014/4, p. 8).

Verificamos nos excertos apresentados que o cuidado, o respeito, a atenção e o apoio da família foram enaltecidos como cruciais para a vida da mulher/acadêmica em questão. No início do memorial (2014/4, p. 3) ela já enfoca a importância da família na vida da criança, atribuindo a essa figuração a pessoa que se constituiu. Posteriormente, no memorial (2014/4, p. 8), surge o relato de uma situação bastante aguda vivida na sua infância. Diante os fatos explicitados precisamos aludir que algo diverso do apoio incondicional da família poderia ter gerado uma continuidade dos abusos e, possivelmente, teria deixado uma marca ainda mais profunda e de difícil superação.

Contudo, para além do impacto causado pelo relato em questão, escolhemos chamar atenção para o trecho da história quando ela realça a tristeza e a amargura que sente pela lembrança e de como essa situação de violência não foi mais falada com ninguém ao longo da sua vida, a exceção daquele primeiro momento com os pais. Ou seja, o não falar, o acontecimento

${ }^{1}$ Registramos que Norbert Elias vivenciou um reconhecimento tardio da sua obra a qual, em certa medida, até hoje ainda é pouco conhecida por muitos estudiosos. Para ver mais sobre a vida e trajetória do autor indicamos Ribeiro (2010), Setton (2013) e Veiga (2011).

\section{(c)(1)}


que precisa permanecer intocado, resguardado é bastante expressivo para nossas discussões, pois sabemos o quanto crianças e mulheres continuam em situações vulneráveis e correndo muito riscos em suas casas. São os assuntos tabus sobre os quais fazem valer, segundo Elias (2011, p. 169), a "conspiração do silêncio", pois continuam atuantes e presentes os discursos conservadores, religiosos, jurídicos, médicos entre outros, os quais ameaçam com constrangimento, medo e vergonha as vítimas de maus tratos de gênero.

Apreendemos tratar-se do histórico discurso encrustado no poder patriarcal que "[...] construiu 'verdades' sobre o feminino que alimentaram a desigualdade de gênero" (COLLING, 2014, p. 10), o qual tenta de maneira ininterrupta garantir a não visibilidade, o silenciamento, o confinamento no espaço privado, enfim, segregar mulheres aos lugares de esposa e mãe, pois estes foram naturalizados como sendo destinos de todas. E como temos assistido e lido em diferentes fontes de informações, as consequências de tal realidade é o aumento dos casos de abusos e mortes em todo o Brasil e especificamente no Mato Grosso do Sul, como apontamos anteriormente no documento da Coordenadoria Estadual da Mulher em Situação de Violência Doméstica e Familiar (MATO GROSSO DO SUL, 2019).

Isto posto, é mister sobrelevarmos a dimensão da escrita do memorial (auto)biográfico, contexto gestado pela professora na universidade do Mato Grosso do Sul, pois tal metodologia possibilitou à mulher/acadêmica, durante sua formação inicial, uma oportunidade na qual ela se sentiu confiante para trazer à tona fatos significativos da sua vivência, cujas lembranças evidenciaram impactos na sua vida. Ponderando na perspectiva da formação de uma futura professora, enaltecemos a conjuntura que lhe permitiu, quiçá, ter enxergado a vulnerabilidade das crianças, das meninas em especial, o que nos leva a apontar a pertinência desse momento de escrita do memorial (auto)biográfico para ressignificar vivências subjetivas que poderão se refletir em ações e posturas frente à educação e ao cuidado para com as infâncias.

Ao adentrarmos em mais algumas discussões acerca das relações de gênero, observamos nas histórias recriadas pelas mulheres/acadêmicas, como surgem nuances, sentidos, singularidades, bem como emergem os indivíduos que formam suas redes na família. Estes [indivíduos] se mostram imbrincados em diferentes constituições e relações, nas quais é possível percebermos desequilíbrios no gradiente de poder.

Por esse ângulo escolhemos trazer os trechos que doravante vão aparecer aqui no texto, pois neles estão registradas histórias de desigualdades relativas ao nascimento de meninas e meninos na família.

Pra angústia do meu pai, ele quase enfartou, xingou minha mãe, como se ela fosse culpada de ter escolhido o sexo, minha mãe apanhou, sofreu agressões, pelo simples fato de ter colocado ao mundo três meninas perfeitas e com saúde, não era o que importava ao meu pai, ele simplesmente deseja o tão sonhado menino. (Memorial de infância, 2013/1, p. 3). 
Um ano depois do casamento de minha mãe nasceu minha primeira irmã [...]. Não demorou muito, minha mãe logo engravidou de novo e no outro ano nasceu minha outra irmã [...] só lembro que minha família não parava de crescer e um ano depois minha mãe engravida novamente, outra menina [...] finalmente minha mãe resolver operar para não ter mais filhos, desistiu de tentar ter um filho homem, que era o sonho do meu pai. (Memorial de infância, 2014/3, p. 3).

É estarrecedor, por isso necessário que nos ocupemos do debate das situações escritas nos memoriais (auto)biográficos, porque agressões, ameaças, coerções, imposições são expostas e se mostram recorrentes, quando o desejo, o "sonho" do nascimento do filho homem não é concretizado. A partir desse cenário precisamos retornar às intermináveis histórias de violências, pois fica patente o valor inferior atribuído às mulheres, demonstrado aqui pelos horrores e sofrimentos causados quando nasce mais uma menina na família.

Como apreendemos em Scott (1995), gênero é um conceito histórico, cultural vinculado à forma como a sociedade constrói as diferenças sexuais e, nesse sentido, compreendemos a atribuição de condições desiguais a homens e mulheres. O prestígio conferido à chegada de um menino é muito superior pela ótica do poder que se origina de uma sociedade machista, constituída sob a égide do preconceito de gênero. Portanto, entendemos que para se efetivar uma mudança nessa realidade que se arrasta e se repete, demandamos a luta dos indivíduos nas mais diversas figurações envolvidas nesses processos sociais, as quais possam garantir respeito aos direitos humanos e uma educação de qualidade, socialmente referenciada que venha possibilitar discussões relativas à temática das relações de gênero [nosso foco aqui] e, obviamente, à todas as demais diversidades sobre as quais foram forjadas verdades. Pela nossa compreensão, se elas foram construídas, precisarão e poderão ser desconstruídas, para que relações equânimes possam ser significadas e passem a fazer parte da vida de todas e todos.

A vigilância e os cuidados excessivos em relação às meninas também se pronunciam nas histórias e em seguida traremos dois excertos nos quais as mulheres/acadêmicas demonstraram o quanto tais circunstâncias dificultaram e marcaram suas vidas.

Não podíamos ter coleguinhas e de forma alguma levá-los para casa, meu pai não admitia, sempre falava que amizade era e existia apenas entre nós três [as irmãs] o nosso caminho era traçado de casa para a escola, e da escola para casa. Meninos então em hipótese alguma, não podíamos nem olhar para um. (Memorial de infância, 2013/1, p. 7, acréscimo nosso).

Tive muitos momentos ruins na minha infância, tive solidão, tive muitas tristezas, na família. Vivi momentos de desavença em casa, e momentos de repreensão. Não fui muito apegada a minha mãe, era mais ao meu pai. Mas com o tempo talvez pelo ciúme me sentisse sufocada com excesso de cuidados e vigilância da minha 
vida, fui perdendo esse apego com ele. Talvez por ser filha mulher, mas eu acabei ficando sem meu espaço, ou privacidade, e isso me fez se afastar dos meus pais na infância [...]. (Memorial de infância, 2013/5, p. 6).

Por que ter a vida cerceada, limitada à casa e à escola, precisar conviver com imposições severas à liberdade, chegando ao ponto de não ter colegas fora do círculo familiar, ser coibida a nem olhar para meninos? E em outro contexto de infância, por que se sentir sozinha, triste, sufocada, sem privacidade, até desistir de conviver com os pais? A resposta se manifesta no próprio relato, "por ser filha mulher". São tratamentos desiguais, desrespeitosos, indignos, os quais apontam para uma sociedade hierarquizada, adultocêntrica, androcêntrica e desumanizadora. As mulheres/acadêmicas trouxeram lembranças dolorosas, de opressão, nas quais enxergarmos ressentimentos pelas perdas do que poderiam ter vivido, experenciado, sentido. Ou seja, em muitas famílias elas foram usurpadas de uma vida plena, de uma vida de direitos pelo fato de serem meninas.

Para finalizarmos esta seção, traremos a seguir três excertos cujos registros tratam de circunstâncias familiares e acontecimentos que marcaram as mulheres/acadêmicas os quais nos propiciam refletir acerca de transformações em curso.

[...] comecei a entender melhor o sofrimento da minha mãe, trabalhava muito e ganhava pouco, mal dava para comermos [...] mas o que valeu a pena é saber que minha mãe nunca me abandonou [...] a infância prefiro mesmo esquecer, e entendo por que atualmente se luta tanto para se defender o direito da criança de viver a infância. (Memorial de infância, 2014/1, p. 7).

[...] foi assim até meus 9 anos, quando nos mudamos para a cidade pois minha mãe já não aguentava mais trabalhar (ela acumulava várias funções), contra a vontade do meu pai que continuou, eles ficaram separados por uns três meses, nós na cidade ele no sítio. [...] enquanto criança não imaginava o sofrimento da minha mãe que trabalhava dia e noite, hoje entendo. (Memorial de infância, 2016/1, p. 4-5).

Na minha casa [...] meus pais estavam brigando muito, pois minha mãe havia passado em um concurso público para merendeira da escola [...], meu pai não queria que ela trabalhasse, mas teve que aceitar [...] Meu pai teve que lidar com o orgulho que ele tanto tinha em querer ser o 'provedor do sustento familiar' [...]. (Memorial de infância, 2016/2, p. 9-11).

Percebemos que as mulheres/acadêmicas, ao registrarem sobre as mudanças que aconteceram na família a partir das ações de suas mães perante suas dificuldades na vida, demonstraram o entendimento de que transgredir o que está posto é difícil, mas necessário se quisermos transformar nossa história e as histórias de outras meninas, outras mulheres, bem como de todas as 
infâncias. Ou seja, reescrever caminhos pressupõe escolhas e para tal, muitas vezes precisaremos ir de encontro, divergirmos das diversas dimensões que nos formam e (con)formam (SARAT; CAMPOS, 2014).

Rememorar a infância e encontrar as marcas deixadas pelas inúmeras experiências foi por muitas vezes registrado como bastante dificultoso e doloroso para as mulheres/acadêmicas. Porém, precisamos considerar que tal vivência pode ter se constituído em uma maneira de ajudá-las a entender suas vidas no presente, a defrontarem com práticas conservadoras que as impuseram/impõem vidas ceifadas, possibilitando romper com o que está posto e, assim, vislumbrarem tempos de emancipação.

\section{Considerações finais}

Neste pequeno arquivo, venho contar resumidamente um pouco de minha infância, tudo o que me lembro, e tudo que me veio a me recordar, minhas memórias de infância, me trouxeram muitas lembranças boas e ruins, mas que são somente minhas, e que venho agora dividir com você leitor de minha história. (Memorial de infância, 2013/1, Capa, grifo nosso).

Em um país no qual Marielle e outras milhares de mulheres são mortas por serem combativas, por quererem ser e viver do modo que escolheram, por optarem em não permanecer casadas e/ou com os companheiros, dentre tantas ditas motivações e justificativas para os crimes que nos assolam, temos a incumbência de não deixar que dias, meses e anos se passem conosco escrevendo as mesmas histórias.

Nossa escolha neste texto foi trabalhar com memoriais de infância (auto)biográficos de mulheres/acadêmicas, identificando e problematizando relações de gênero na família, nas quais compreendemos existirem históricas relações desiguais de poder. Esperamos que nossas discussões possam contribuir para diminuir e, quiçá, superar a dominação masculina que impede o pleno desenvolvimento humano de crianças, mulheres e também de homens.

Concebemos os estudos e as políticas de gênero como inovadores e extremamente necessários e mesmo que sofram seguidos ataques já há algum tempo em nosso país, precisamos reiterar que eles são eticamente desejáveis, pois sem eles não vivenciaremos o planejamento $e$, consequente, $a$ implementação das políticas públicas que possam transformar as relações sociais de opressão e efetivamente concorrer para a erradicação das violências.

Aprendemos com Elias (2011, p. 70), que "a 'civilização' que estamos acostumados a considerar como uma posse que aparentemente nos chega pronta e acabada, sem que perguntemos como viemos a possuí-la, é um processo, ou parte de um processo em que nós mesmos estamos envolvidos". Quer seja, é uma história que vem processada por longo período, por meio de um movimento lento, quase imperceptível, o qual por vezes temos o ímpeto de tomar como natural, porém é construído no decorrer dos séculos, não apresentando uma linearidade e, muito menos carregando uma ideia de progresso. 
Portanto, avanços e recuos fazem parte da construção de uma realidade na qual, compreendemos, todos os indivíduos precisarão lutar para terem sua humanidade respeitada e preservada. Concluímos destacando que, para cuidarmos do outro precisamos antes nos cuidar, nos humanizar, lutar pela nossa dignidade e pelo direito de existirmos.

\section{REFERÊNCIAS}

AMARAL, Maxwell da Silva. A marcha para o oeste e a colonização da fronteira sul do atual Mato Grosso do Sul: deslocamentos, políticas e desafios.

Fronteiras: Revista de História | Dourados, MS | v. 16 | n. 28 | p. 153 - 165 | 2014. Disponível em:

https://ojs.ufgd.edu.br/index.php/FRONTEIRAS/article/view/4549. Acesso em: 20 fev. 2021.

ALVES, Hildinéia; PESTANA, Marcela; MARQUES, Antonio Francisco. Gênero e Educação Infantil: entre princesas e príncipes há crianças que brincam e sonham. Perspectivas em Diálogo: Revista de educação e sociedade, Naviraí, v. 7, n. 14, p. 129-147, jan./jun. 2020. Disponível em: https://periodicos.ufms.br/index.php/persdia/article/view/9319. Acesso em: 23 fev. 2021.

BELLOTO, Heloísa Liberalli. Arquivos permanentes: tratamento documental. 4. ed. Rio de Janeiro: FGV, 2015.

BITTAR, Marisa. Mato Grosso do Sul, a construção de um estado. v. 1: Regionalismo e divisionismo no sul de Mato Grosso. Campo Grande: Ed. UFMS, 2009a.

BITTAR, Marisa. Mato Grosso do Sul, a construção de um estado. v. 2: Poder político e elites dirigentes sul-mato-grossenses. Campo Grande: Ed. UFMS, 2009b.

BUENO, Belmira Oliveira. O método autobiográfico e os estudos com histórias de vida de professores: a questão da subjetividade. Educação e Pesquisa, São Paulo, v.28, n .1, p. 11-30, jan./jun. 2002. Disponível em: https://www.scielo.br/pdf/ep/v28n1/11653.pdf. Acesso em: 09 nov. 2017.

BRASIL. Lei no 8.159, de 8 de janeiro de 1991. Dispõe sobre a política nacional de arquivos públicos e privados e dá outras providências. Brasília, 1991. Disponível em: http://www.planalto.gov.br/ccivil_03/leis/L8159.htm. Acesso em: 26 out. 2017.

CAMPOS, Míria Izabel. Tempos de Escritas: memoriais de infância, docência e gênero. 188f. Tese (Doutorado em Educação) - Universidade Federal da Grande Dourados (UFGD). Dourados, MS, 2018. 
CHIAVENATTO, Júlio José. O golpe de 64 e a ditadura militar. São Paulo, SP: Moderna, 1995.

COLLING, Ana Maria. Tempos diferentes, discursos iguais: a construção histórica do corpo feminino. Dourados, MS: Ed. UFGD, 2014.

CUNHA, Maria Tereza Santos. O arquivo pessoal do professor catarinense Elpídio Barbosa (1909-1966): do traçado manual ao registro digital. Hist. Educ. (Online), Porto Alegre v. 21 n. 51 jan./abr., 2017. p. 187-206. Disponível em: https://www.redalyc.org/pdf/3216/321648890010.pdf. Acesso em: 09 jun. 2016.

DUCROT, Ariane. A classificação dos arquivos pessoais e familiares. FGV. Estudos Históricos, n. 21, p. 151-168, 1998. Disponível em: https://bibliotecadigital.fgv.br/ojs/index.php/reh/article/view/2059. Acesso em: Acesso em: 26 out. 2017.

ELIAS, Norbert. A Sociedade dos indivíduos. Organizado por Michael Schröter. Tradução Vera Ribeiro. Revisão técnica e notas Renato Janine Ribeiro. Rio de Janeiro: Zahar, 1994.

ELIAS, Norbert. Norbert Elias por ele mesmo. Tradução André Telles. Rio de Janeiro: Jorge Zahar, 2001.

ELIAS, Norbert. Introdução à sociologia. Reimp. - (Biblioteca 70; 16). Biblioteca Nacional de Portugal - Catalogação na Publicação, 2008.

ELIAS, Norbert. O processo civilizador: uma história dos costumes. Volume 1. 2. ed. Tradução Ruy Jungmann. Revisão e apresentação Renato Janine Ribeiro. Rio de Janeiro: Zahar, 2011.

ELIAS, Norbert. A civilização dos pais. Revista Sociedade e Estado, v. 27, n. 3, p. 469-493, set./dez. 2012. Disponível em:

https://www.scielo.br/j/se/a/d8cs7Bb6zx8n83kgYdP7kRH/?lang=pt. Acesso em: 12 nov. 2016.

ELIAS, Norbert. A mudança na relação de poder entre os sexos - um estudo sociológico processual: o exemplo do Antigo Estado Romano. Tradução: Ana Flávia Braun Vieira (UEPG). In: VIEIRA, Ana Flavia Braun. FREITAS JUNIOR, Miguel Archanjo de (Orgs.). Norbert Elias em debate: usos e possibilidades de pesquisa no Brasil. Ponta Grossa/PR: Texto e Contexto, 2020. (Coleção Singularis, v.6).

FERREIRA, Jorge; GOMES, Angela de Castro. 1964: o golpe que derrubou um presidente, pôs fim ao regime democrático e instituiu a ditadura no Brasil. Rio de Janeiro: Civilização Brasileira, 2014. 
JOSSO, Marie-Christine. Histórias de vida e formação: suas funcionalidades em pesquisa, formação e práticas sociais. Revista Brasileira de Pesquisa (Auto)Biográfica, Salvador, v. 05, n. 13, p. 40-54, jan./abr. 2020. Disponível em: https://www.revistas.uneb.br/index.php/rbpab/article/view/8423/5390.

Acesso em: 13 jun. de 2020.

MATO GROSSO DO SUL. Feminicídio: Relatório Estatístico do Poder Judiciário. Coordenadoria Estadual da Mulher em Situação de Violência Doméstica e Familiar. Documento do Tribunal de Justiça de Mato Grosso do Sul. Campo Grande/MS Disponível em:

https://www5.tjms.jus.br/_estaticos_/sc/publicacoes/relatorio-feminicidio2019.pdf. Acesso em: 02 fev. 2021.

OLIVEIRA, Benícia Couto de. O Estado Novo e a nacionalização das fronteiras: a ocupação estratégica do Sul de Mato Grosso. Fronteiras: Revista de História. Dourados, 2002. Disponível em: https://ojs.ufgd.edu.br/index.php/FRONTEIRAS/article/view/13458. Acesso em: 20 fev. 2021.

PASSEGGI, Maria da Conceição; SOUZA, Elizeu Clementino; VICENTINI, Paula Perin. Entre a vida e a formação: pesquisa (auto)biográfica, docência e profissionalização. Educação em Revista | Belo Horizonte, v. 27, n. 1, p. 369-386, abr. 2011. Disponível em:

https://www.scielo.br/scielo.php?pid=S0102-

46982011000100017\&script=sci_abstract\&tlng=pt. Acesso em: 01 nov. 2017.

RIBEIRO, Luci Silva. Processo e figuração: um estudo sobre a sociologia de Norbert Elias. 2010. 281 f. Tese (Doutorado em Sociologia) - Universidade Estadual de Campinas. Campinas/SP, 2010.

SARAT, Magda; CAMPOS, Míria Izabel. Gênero, sexualidade e infância: (Con)formando meninas. Revista Tempos e Espaços em Educação. v. 7, n. 12, jan./abr. 2014. Disponível em:

https://seer.ufs.br/index.php/revtee/article/view/2951. Acesso em: 11 jul. 2016.

SCOTT, Joan W. Gênero: uma categoria útil de análise histórica. Educação \& Realidade, v. 2 n. 16, p. 5-22, julho/dezembro. 1995. Disponível em: https://seer.ufrgs.br/index.php/educacaoerealidade/article/view/71721. Acesso em: 02 jul. 2017.

SETTON, Maria da Graça Jacintho. Marcel Mauss e Norbert Elias: notas para uma aproximação epistemológica. Educ. Soc., Campinas, v. 34, n. 122, p. 195-210, jan./mar. 2013. Disponível em: http://www.cedes.unicamp.br. Acesso em: 12 jan. 2016. 
SILVA, Marcos. Brasil, 1964/1968: a ditadura já era ditadura. São Paulo, SP: LCT, 2006.

SOUZA, Elizeu Clementino. A arte de contar e trocar experiências: reflexões teórico-metodológicas sobre história de vida em formação. Revista Educação em Questão, Natal, v. 25, no 11, p. 22-39, jan/abr, 2006. Disponível em: https://periodicos.ufrn.br/educacaoemquestao/article/view/8285. Acesso em: 10 abr. 2017.

VEIGA, Cynthia Greive. O processo escolarizador da infância em Minas Gerais (1835-1906): geração, gênero, classe social e etnia. In: OLIVEIRA, Lindamir C. V.; SARAT, Magda (Orgs.). Educação infantil: história e gestão educacional. Dourados/MS: Editora da UFGD, 2009.

VEIGA, Cynthia Greive. Pensando com Elias as relações entre Sociologia e a História da Educação. In: FARIA FILHO, Luciano Mendes (Org.). Pensadores sociais e História da Educação. 3. ed. Belo Horizonte: Autêntica, 2011, p.139-166.

\section{FONTES CITADAS}

Memorial de infância, 2013/1, Dourados - nascimento 1985.

Memorial de infância, 2013/3, Dourados - nascimento 1989.

Memorial de infância, 2013/5, Dourados - nascimento 1995.

Memorial de infância, 2014/1, Caarapó - nascimento 1980.

Memorial de infância, 2014/3, Dourados - nascimento 1982.

Memorial de infância, 2014/4, Fátima do Sul - nascimento 1988.

Memorial de infância, 2016/1, Dourados - nascimento 1990.

Memorial de infância, 2016/2, Dourados - nascimento 1994.

Memorial de infância, 2016/4, Fátima do Sul - nascimento 1996.

Recebido em: 03 de maio de 2021. Aceito em: 25 de maio de 2021. Publicado em: 30 de junho de 2021. 